\title{
Sprayer for chemical treatment of vineyards and orchards
}

\author{
Muxtor Xalilov ${ }^{*}$, and Rustam Yusupov \\ Karshi Engineering Economic Institute, Karshi, Uzbekistan
}

\begin{abstract}
The authors have developed an improved sprayer for two-way chemical treatment of vineyards and orchards. The research aims to justify the design scheme and parameters of the sprayer. The proposed sprayer is equipped with a centrifugal fan, which directs air flow from the inlet window to two opposite sides. The distributor is designed as a truncated cone with an inlet nozzle on its small base and outlet nozzles equally spaced on its large base and connected to sprayers by flexible hoses of equal length. It is established that the diameter of the centrifugal fan wheel $630 \mathrm{~mm}$, number of fan wheel rotations $1500 \mathrm{r} / \mathrm{min}$, diameters of large and small distributor base as a truncated cone $90 \mathrm{~mm}$ and $18 \mathrm{~mm}$ respectively, the diameter of each nozzle set on its large base $3 \mathrm{~mm}$, cone height 100 $\mathrm{mm}$, number of atomizers 20 pieces and working liquid pressure in the system $0.40-0.45 \mathrm{MPa}$ is provided a uniform distribution of working liquid.
\end{abstract}

\section{Introduction}

The development and implementation of energy-saving and high-performance machines for soil tillage [1-20], sowing [21-23], and chemical treatments against crop pests and diseases [24-27] are currently leading the way worldwide. Special attention is paid to the development of machines and implements for primary and pre-sowing inter-row tillage [28] and the chemical treatment of vineyards and orchards with high work quality and efficiency [29-30]. Studies on creation and implementation of justification of parameters of working bodies of fans and sprayers for chemical treatment of plants were conducted by O.Ivanov [36], O.Mamchenko [36], M.Nevelson [33], M. Kalinushkin [35], B.Turbin [37], V.Cherkassky [38], I.Beletsky [39], A.Lysov [39], N.Lepekhin [39], T.Solomakhova [40], K.Chebysheva [40], D.Dzhuraev [31-32], I. Ashirbekov [41], Kh.Irisov [41] and others.

The machines and devices for chemical treatment of plants created due to these studies are used with some positive results in agricultural production. However, these studies have not sufficiently explored the issues of improving and justifying the parameters of the sprayer in the direction of reducing energy consumption and improving the quality of work.

Based on the analysis of research work and studies conducted, the design scheme of an improved sprayer, which carries out two-way treatment of inter-row orchards in one pass, has been developed.

The study aims to justify the design and parameters of the sprayer.

*Corresponding author: xmuxtor83@mail.ru 


\section{Methods}

The mounted sprayer consists of frame, tank, pump, filters, regulators, distributor, fan, atomizer, and transmission mechanisms (Fig.1). The advantage of the proposed sprayer compared to existing sprayers is that it is equipped with a centrifugal fan, which sucks the flow of air from the inlet window and directs it to two opposite directions. The distributor is made in the form of a truncated cone, which is connected to sprayers according to the new technological scheme. As a consequence, a two-way, high-quality chemical treatment of the inter-row orchards is ensured.

Sprayer's distributor 1 (Fig.2) is designed as a truncated cone with an inlet nozzle on its small base and outlet nozzles, evenly spaced on the large base 2 and connected by flexible hoses 3 of equal length with sprayers 7, fixed inside the nozzle on the bracket with the possibility of movement.

The uniform distribution of the spray liquid over the nozzles, irrespective of their arrangement and number, increases the efficiency of the sprayer. The following conditions are met for a good chemical treatment.

$$
q_{1}=q_{2}=q_{3}=q_{4}=q_{5}=q_{6}=q_{7}=\ldots=q_{n},
$$

where $q_{1}, q_{2}, q_{n}$ are, respectively, the spray rate of the first, second, and nd sprayer.

The mounted sprayer works as follows (Fig.1). Wheels 19 of the fan, driven by the tractor PTO through the V-belt transmission, draws air flows from the cowl inlet window 19 and directs them in two opposite directions at a certain pressure and speed.

The working parts 20 installed in the side outlet windows direct the air flow at a certain speed to the object to be treated.

The working fluid, under defined pressure, is supplied by pump 5 through a fine filter 9 by flexible hoses 2 to distributor 14. According to Pascal's law, the working fluid enters the distributor 14 and generates a certain pressure over the entire internal area, which spreads evenly.
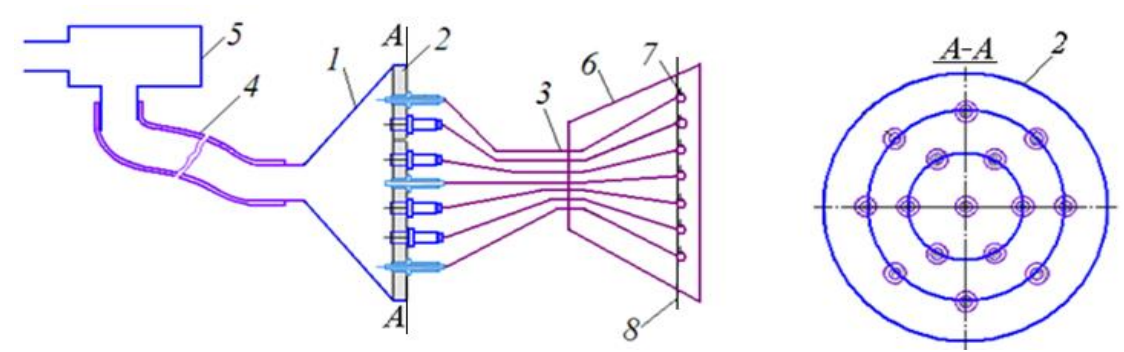

Fig. 1. Process diagram of distributor and connection diagram of atomizers: 1 - distributor;

2 is large base of truncated cone; 3-4 are hoses; 5 is thin filter; 6 is working part-nozzle; 7 are sprayers; 8 is rod

Distributor 14 supplies the working fluid with the same pressure to all nozzles 17, which are individually connected to it. The flow rate to all nozzles is uniform, as shown in equation (1). 

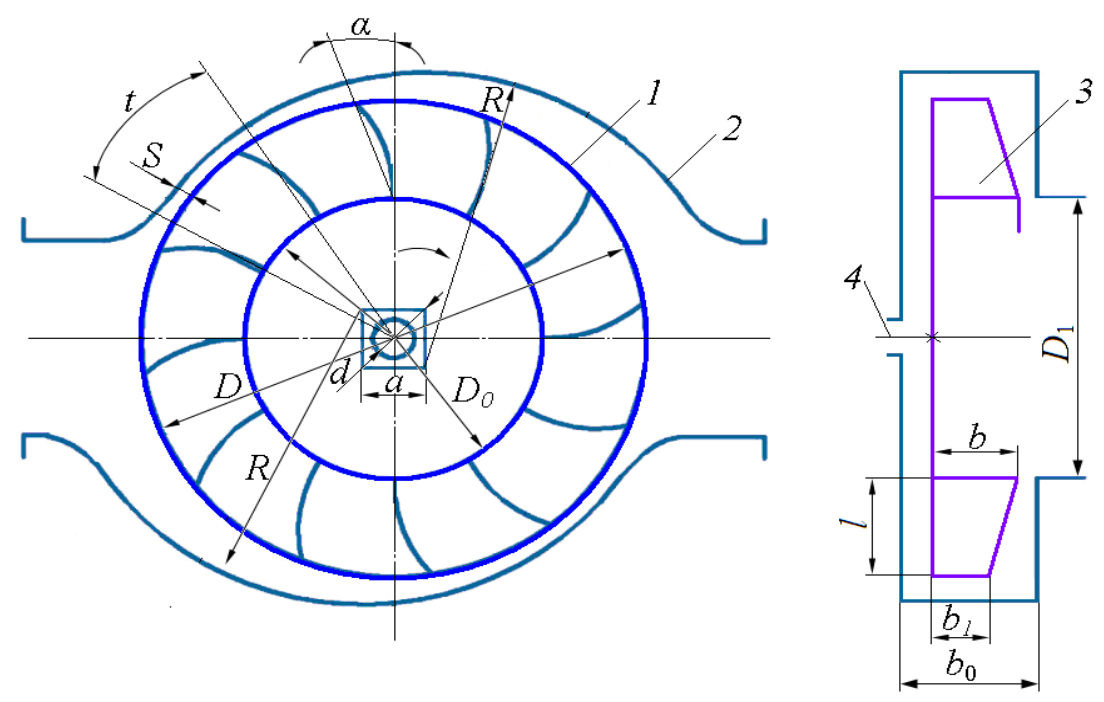

Fig. 2. Parameters of the centrifugal sprayer fan: 1 is fan wheel; 2 is fan casing; 3 is fan blade; 4 is fan shaft

The main parameters for the sprayer fan are as follows (fig.3): $D$ is diameter of the fan wheel, $\mathrm{m} ; D_{0}$ is diameter of air inlet window of the wheel, $\mathrm{m} ; b$ and $b_{1}$ is width of blades, respectively, mounted on the wheel at air inlet and outlet, $\mathrm{m} ; l$ is length of the blade, $\mathrm{m} ; t$ and $Z$ is pitch and number of blades, respectively, $\mathrm{m} ; n$ is number of wheel revolutions, $\mathrm{r} / \mathrm{s}$; $b_{0}$ and $D_{1}$ is width and diameter of casing window correspondingly at air inlet, m; $S$ is width of gap between casing outlet window rib and wheel, $\mathrm{m} ; R$ is radius of casing curvature, $\mathrm{m}$.

A centrifugal fan basically consists of two parts: a wheel and a casing. The fan wheel is taken as a closed and truncated cone. At that, air entering the fan inlet, at the transition to the channels between the fan blades turns by $90^{\circ}$, pressure is insignificantly lost, and efficiency of air entering the space between the blades increases, i.e., high efficiency is reached $\left(\eta_{\max }=0,8-0,9\right)$.

Fan diameter $D$, the diameter of air suction window $D_{0}$, the number of blades $Z$, blade pitch $t$ are determined by the following expressions proposed by V.Cherkassky [39]

$$
\begin{aligned}
& D=K \sqrt[3]{\frac{Q}{60 n}}, \\
& D_{0}=0.54 D, \\
& Z \geq \pi \frac{D+D_{0}}{D-D_{0}} . \\
& t=\frac{\pi\left(D+D_{0}\right)}{2 Z} .
\end{aligned}
$$

where $K$ is dimensionless coefficient; $Q$ is fan capacity, $\mathrm{m} 3 / \mathrm{s} ; n$ is fan speed, $\mathrm{r} / \mathrm{s}$.

At $K=4.25, Q=3.52 \mathrm{~m} 3 / \mathrm{s}$ and $n=25 \mathrm{r} / \mathrm{s}$ on the base of calculations according to expressions (2), (3), (4), and (5), we assume diameter of fan wheel $D=0.63 \mathrm{~m}$, diameter of suction window air $D_{0}=0,34 \mathrm{~m}$, number of blades $Z=12$, step of blades installation $t=127$ $\mathrm{mm}$.

The diameter of an outlet window $D_{1}$ of the shell is taken equal to the diameter of an inlet window, $D_{1}=D_{0}=0.34 \mathrm{~m}$.

Aerodynamic characteristics of the air flow coming from the working parts mounted on 
the fan hood directly affect the quality of the spray of the working fluid. On this basis, determined the speed of air flow $V_{2}$, created by the fan at the exit of the working parts and the pressure $P_{2}$, as well as the lost part of the pressure $P_{p . t r}$

$$
\begin{gathered}
V_{2}=\frac{V_{1} S_{1}}{S_{2}} k_{1}, \\
P_{2}=\frac{\gamma V_{2}^{2}}{2}, \\
P_{p . t r}=\frac{\left[0,025 a_{k} b_{k}+0,0011 k_{e}\left(a_{k}+b_{k}\right)\right] Q^{2}\left(a_{k}+b_{k}\right) l \gamma}{8\left(a_{k} b_{k}\right)^{4}}+k_{1} \frac{Q^{2}}{\left(a_{k} b_{k}\right)^{2}}
\end{gathered}
$$

where $a$ and $b$ are dimensions of the working part window; $V_{1}$ and $V_{2}$ is respectively average air velocity at the inlet and outlet of the working part window, m/s; $S_{1}$ and $S_{2}$ is respectively area of inlet and outlet window of the working part, $\mathrm{m} 2 ; k_{1}$ is factor, taking into account the decrease in air pressure at the outlet of the working part, to the inlet pressure; $\gamma$ is air density, $\mathrm{kg} / \mathrm{m}^{3}$.

The total power consumed for the technological process of the sprayer for chemical treatment consists of the power consumption for overcoming the useful resistance for creating the air flow in the fan, the power for overcoming the harmful resistance in the bearings and the drive of the $V$-belt gears, as well as for the pump drive. The power consumption for the fan drive is determined by the following formula

$$
N_{0}=a h v_{\text {ave }}^{3} \gamma\left(2-\eta_{1}^{3} \eta_{2}^{2}\right)
$$

where $v_{\text {ave }}$ is average air velocity, $\mathrm{m} / \mathrm{s} ; \eta_{1}$ is efficiency factor of one pair of bearings; $\eta_{2}$ is efficiency factor of $V$-belt transmission.

The analysis of expression (13) shows that the power consumed by the fan drive, depending on the size of the outlet window of the air flow, air flow rate, and the efficiency of links in the gears. The calculations made by expression (13) show that the total power is in the range $N_{0}=170.6-4810.7 \mathrm{~W}$ for air velocity in the range $11.5-35 \mathrm{~m} / \mathrm{s}$.

\section{Results and Discussion}

In experimental studies, using a specially made advanced tube, to determine the pressure and speed of air, and installation, studied the impact of the number of revolutions of the fan, an improved sprayer on air flow parameters at the outlet of the window shroud, and working part, and power consumption fan, the speed of the unit, and the number of revolutions of the fan on air speed at the inlet and outlet of the vine, as well as parameters of the spreader at the flow rate and uniform distribution of the air flow.

The results of these studies showed that with the increasing number of revolutions of the fan wheel, the pressure of the air flow at the outlet of the casing window and the working part of the fan increases in a parabola, and the flow rate and air velocity - in a straight line. For example, an increase in fan speed from $800 \mathrm{r} / \mathrm{min}$ to $1600 \mathrm{r} / \mathrm{min}$ air pressure at the outlet of the cowl window has increased 5,5 times, and its speed 2,3 times. Accordingly, from the above, an increase in air flow rate of 2-3 times.

According to research results at the speed of the fan wheel $1500 \mathrm{r} / \mathrm{min}$ and air flow rate at the outlet of the fan $v_{P}=27.1 \mathrm{~m} / \mathrm{s}$, the air speed at the entrance to the vineyard was $v_{T K}=15.2 \mathrm{~m} / \mathrm{s}$, and on the way out $-v_{T C H}=2.5-4.0 \mathrm{~m} / \mathrm{s}$. Proceeding from the above number of 
revolutions of the fan wheel is taken $1500 \mathrm{r} / \mathrm{min}$.

The results of experiments on the influence of the type of distributor on the flow rate of sprayed liquid and uniformity of its distribution are given in the table. The given data show that the suggested distributor in the form of a truncated cone at a pressure within $0,1-0,8$ $\mathrm{MPa}$ provides an almost uniform distribution of working liquid from all nozzles. Uniformity of distribution of working liquid by atomizers from the distributor, in the form of a truncated cone, is \pm 5 , and for atomizers from the distributor, in the form of a vertical pipe, $-28 \%$. Therefore, based on the results of the experiments conducted, it is advisable to use a truncated cone distributor on the sprayer.

Table 1. Influence of distributor type on chemical flow distribution to the atomiser nozzles Test point Pressure, MPa 1-tip, $l / \mathrm{min} 2$-tip, $l / \mathrm{min}$

\begin{tabular}{|c|c|c|c|c|c|c|c|c|}
\hline \multirow{2}{*}{$\begin{array}{c}\text { Experimental point } \\
\text { number }\end{array}$} & \multicolumn{8}{|c|}{ Pressure, $\mathrm{MPa}$} \\
\hline & 0.1 & 0.2 & 0.3 & 0.4 & 0.5 & 0.6 & 0.7 & 0.8 \\
\hline \multirow{2}{*}{ 1- handpiece, $l / \mathrm{min}$} & 1.42 & 1.71 & 2.01 & 2.42 & 2.80 & 3.21 & 3.92 & 4.84 \\
\hline & 1.54 & 1.76 & 1.96 & 2.15 & 2.6 & 2.91 & 3.64 & 4.48 \\
\hline \multirow{2}{*}{ 2- handpiece, $l / \mathrm{min}$} & 1.40 & 1.65 & 1.95 & 2.38 & 2.71 & 3.15 & 3.83 & 4.61 \\
\hline & 1.54 & 1.72 & 1.99 & 2.2 & 2.5 & 3.12 & 3.7 & 4.52 \\
\hline \multirow{2}{*}{ 3- handpiece, $l / \mathrm{min}$} & 1.35 & 1.62 & 1.80 & 2.34 & 2.50 & 2.95 & 3.64 & 4.56 \\
\hline & 1.56 & 1.8 & 1.98 & 2.11 & 2.56 & 3.1 & 3.72 & 4.5 \\
\hline \multirow[t]{2}{*}{ 4- handpiece, $l / \mathrm{min}$} & 1.25 & 1.51 & 1.84 & 2.20 & 2.41 & 2.89 & 3.48 & 4.41 \\
\hline & 1.58 & 1.83 & 2.02 & 2.09 & 2.48 & 3.16 & 3.74 & 4.5 \\
\hline \multirow[t]{2}{*}{ 5- handpiece, $l / \mathrm{min}$} & 1.20 & 1.45 & 1.71 & 2.01 & 2.32 & 2.80 & 3.11 & 4.21 \\
\hline & 1.59 & 1.75 & 1.95 & 2.22 & 2.45 & 3.2 & 3.78 & 4.56 \\
\hline \multirow[t]{2}{*}{ 6- handpiece, $l / \mathrm{min}$} & 1.05 & 1.25 & 1.52 & 1.91 & 2.26 & 2.61 & 3.21 & 3.82 \\
\hline & 1.61 & 1.82 & 2.01 & 2.2 & 2.52 & 3 & 3.84 & 4.64 \\
\hline
\end{tabular}

Numerator - with vertical pipe spreader; denominator - with truncated cone spreader

In the tests, the developed prototype sprayer performed reliably in the specified technological process, and its performance was fully compliant with the requirements.

\section{Conclusions}

1. The sprayer is equipped with a centrifugal fan, which sprays the spraying liquid in two lines. A distributor, making it possible to achieve the required quality chemical treatment of vineyards and orchards.

2. It is established that the diameter of the centrifugal fan wheel $630 \mathrm{~mm}$, a diameter of the air inlet window $340 \mathrm{~mm}$, a blade pitch $127 \mathrm{~mm}$, several blades 12, a diameter of the casing air inlet window $340 \mathrm{~mm}$, and a speed of the fan wheel $1500 \mathrm{r} / \mathrm{min}$ result in quality chemical treatment of vineyards and orchards with minimum power consumption.

3. As a result of researches, it is established that a diameter of a large and small base of the distributor in the form of a truncated cone $90 \mathrm{~mm}$ and $18 \mathrm{~mm}$ respectively, a diameter of each nozzle set on its large base $3 \mathrm{~mm}$, the height of the cone $100 \mathrm{~mm}$, number of nozzles 20 items and pressure of working liquid in the system $0.40-0.45 \mathrm{MPa}$ are provided with the equal distribution of working liquid. 


\section{References}

1. Mamatov, F.M., Eshdavlatov, E., Suyunov, A. The Shape of the Mixing Chamber of the Continuous Mixer // Jour of Adv Research in Dynamical and Control Systems, Vol. 12, 07- (2020). DOI: 10.5373/JARDCS/V12SP7/20202318 ISSN 1943-023X.

2. Mamatov, F., Ergashev, I., Ochilov, S., Pardaev, X. Traction Resistance of Soil Submersibility Type "Paraplau" // Jour of Adv Research in Dynamical \& Control Systems, Vol.12, 07-Special Issue, (2020).

3. Aldoshin, N., Mamatov, F., Ismailov, I., Ergashov, G. Development of combined tillage tool for melon cultivation // 19th international scientific conference engineering for rural development Proceedings, Jelgava, 20,(2020). Volume 19. ISSN 1691-5976. DOI:10.22616/ERDev.2020.19.TF175.

4. Umurzakov, U., Mirzaev, B., Mamatov, F., Ravshanov, H., Kurbonov, S. A rationale of broach-plow's parameters of the ridge-stepped ploughing of slopes // XII International Scientific Conference on Agricultural Machinery Industry IOP Conf. Series: Earth and Environmental Science 403(2019) 012163 IOP Publishing doi:10.1088/1755-1315/403/1/012163.

5. Mirzaev, B., Mamatov, F., Chuyanov, D., Ravshanov, X., Shodmonov, G., Tavashov, $\mathrm{R}$ and Fayzullayev, X. Combined machine for preparing soil for cropping of melons and gourds, XII International Scientific Conference on Agricultural Machinery Industry. doi.org/10.1088/1755-1315/403/1/012158.

6. Mirzaev, B., Mamatov, F., Ergashev, I., Ravshanov, H., Mirzaxodjaev, Sh., Kurbanov, Sh., Kodirov, U and Ergashev, G. Effect of fragmentation and pacing at spot ploughing on dry soils, E3S Web of Conferences 97. doi.org/10.1051/e3sconf/201913501065.

7. Mamatov, F., Mirzaev, B., Shoumarova, M., Berdimuratov, P., Khodzhaev, D. Comb former parameters for a cotton seeder// International Journal of Engineering and Advanced Technology (IJEAT) Volume-9 Issue1 October/ DOI: 10.35940/ijeat.A2932.109119.

8. Mamatov, F., Mirzaev, B., Batirov, Z., Toshtemirov, S., Tursunov, O., Bobojonov, L. Justification of machine parameters for ridge forming with simultaneous application of fertilizers, IOP Conf. Series: Materials Science and Engineering 883(2020) 012165 IOP Publishing. doi:10.1088/1757-899X/883/1/012165.

9. Mirzaev, B., Mamatov, F., Avazov, I., Mardonov, S. Technologies and technical means for anti-erosion differentiated soil treatment system, E3S Web of Conferences. doi.org/10.1051/e3sconf/20199705036.

10. Aldoshin, N., Didmanidze, O., Mirzayev, B., Mamatov, F. Harvesting of mixed crops by axial rotary combines, Proceeding of $7^{\text {th }}$ International Conference on Trends in Agricultural Engineering 2019. $17^{\text {th }}-20^{\text {th }}$ Prague, Czech Republic. - pp.20-26. September (2019).

11. Mirzaev, B., Mamatov, F., Aldoshin, N and Amonov, M. Anti-erosion two-stage tillage by ripper, Proceeding of 7th International Conference on Trends in Agricultural Engineering 17th-20th. Prague, Czech Republic. - pp.391-396. September (2019).

12. Mirzaev, B., Mamatov, F., Ergashev, I., Islomov, Yo., Toshtemirov, B., Tursunov O. Restoring degraded rangelands in Uzbekistan, Procedia Environmental Science, № 6. - pp 395-404. (2019)

13. Uzakov, Z.U., Mamatov, F.M., Begulov, O. Implementation of object-oriented Programming technology in the one-dimensional oil displacement problem, International Conference on information Science and Communications Technologies: ICISCT 2019/0012008. Tashkent, Uzbekistan. INSPEC Accession 
Number: 19412491. DOI: 10.1109/ICISCT47635.2019.9012008.

14. Mamatov, F., Mirzaev, B., Berdimuratov, P., Turkmenov, Kh., Muratov, L., Eshchanova, G. The stability stroke of cotton seeder moulder, IOP Conf. Series: Materials Science and Engineering 883 (2020) 012145 IOP Publishing. doi:10.1088/1757-899X/883/1/012145.

15. Mamatov, F., Mirzaev, B., Tursunov, O. A Justification of Broach-Plow's Parameters of the Ridge-Stepped Ploughing, E3S Web of Conferences 97, 05035 (2019). doi.org/10.1051/e3sconf/20199705035.

16. Ahmedov, B.J., Mirzaev, B.S.,Mamatov, F.M., Khodzhaev, D.A., Julliev, M.K. Integrating of gis and gps for ionospheric perturbations in d- And f-layers using vlf receiver, InterCarto, InterGIS 26, - c. 547-560. DOI: 10.35595/2414-9179-2020-1-26547-560.

17. Mamatov, F., Mirzaev, B., Tursunov, O., Ochilov, S and Chorieva, D. Relief, physicomechanical and technological properties of soil in the cotton growing area // ICECAE 2020. IOP Conf. Series: Earth and Environmental Science 614(2020) 012169. IOP Publishing. doi:10.1088/1755-1315/614/1/012169.

18. Shamsutdinov, Z., Ubaydullaev, Sh., Shamsutdinov, N., Mirzaev, B., Mamatov, F., and Chorshabiyev, N. The concept of the phytogenic field: theory, research experience and practical significance, ICECAE 2020. IOP Conf. Series: Earth and Environmental Science 614(2020) 012164. IOP Publishing. doi:10.1088/1755-1315/614/1/012164.

19. Umurzakov, U., Mamatov, F., Aldoshin, N., and Mirzaev, B. Exploration of tillage technologies in the Republic of Uzbekistan // ICECAE 2020 IOP Conf. Series: Earth and Environmental Science 614(2020) 012168. IOP Publishing. doi:10.1088/17551315/614/1/012168.

20. Mamatov, F., Aldoshin, N., Mirzaev, B., Ravshanov, H., Kurbanov, Sh and Rashidov, N. Development of a frontal plow for smooth, furless plowing with cutoffs, IOP Conf. Series: Materials Science and Engineering 1030 (2021) 012135 IOP Publishing. doi:10.1088/1757-899X/1030/1/012135.

21. Mamatov, F., Mirzaev, B., Mirzahodzhaev, Sh., Uzakov, Z and Choriyeva, D. Development of a front plow with active and passive working bodies // IPICSE 2020. IOP Conf. Series: Materials Science and Engineering 1030 (2021) 012164. IOP Publishing. doi:10.1088/1757-899X/1030/1/012164.

22. Mamato, F.M., Eshdavlatov, E., Suyuno, A. Continuous Feed Mixer Performance //Journal of Advanced Research in Dynamical and Control Systems (JARDCS). Volume-12, 07-Spesia1 Issue, 2020. DOI: 10.5373/JARDCS/V12SP7/20202343. ISSN 1943-023X.

23. Mamatov, F., Ergashev, I., Mirzaev, B., Pardaev, X, Chorieva, D. Research of the Penetration Process of the Frontal Plow, 2nd Bukittinggi International Conference on Education (BICED) 2020. Journal of Physics: Conference Series 1779 (2021) 012002. IOP Publishing. doi:10.1088/1742-6596/1779/1/012002.

24. Kodirov, U., Aldoshin, N., Ubaydullayev, Sh., Sharipov, E., Muqimov, Z and Tulaganov, B. The soil preparation machine for seeding potatoes on comb // CONMECHYDRO - 2020 IOP Conf. Series: Materials Science and Engineering 883(2020) 012143 IOP Publishing doi:10.1088/1757-899X/883/1/012143.

25. Ravshanov, Kh., Fayzullaev, Kh., Ismoilov, I., Irgashev, D., Mamatov, S. The machine for the preparation of the soil in sowing of plow crops under film // CONMECHYDRO - 2020 IOP Conf. Series: Materials Science and Engineering 883(2020) 012138 IOP Publishing doi:10.1088/1757-899X/883/1/012138.

26. Ravshanov, H, Babajanov, L, Kuziev, Sh, Rashidov, N, Kurbanov, Sh. Plough hitch parameters for smooth tails, IOP Conf. Series: Materials Science and Engineering 883(2020) 012139 IOP Publishing doi:10.1088/1757-899X/883/1/012139. 
27. Chuyanov, D., Shodmonov, G.,Avazov, I., Rashidov, N, Ochilov, S. Soil preparation machine parameters for the cultivation of cucurbitaceous crops // CONMECHYDRO - 2020 IOP Conf. Series: Materials Science and Engineering 883(2020) 012139 IOP Publishing doi:10.1088/1757-899X/883/1/012122.

28. Mamatov F.M., Mirzaev B.S., Avazov I.Zh.. Agrotehnicheskie osnovy sozdanija protivojerozionnyh vlagosberegajushhih tehnicheskih sredstv obrabotki pochvy $\mathrm{v}$ uslovijah Uzbekistana // - Prirodoobustrojstvo, (2014).

29. Mamatov F.M., Mirzaev B.S. Erosion preventive technology of crested ladder-shaped tillage and plow design // European Applied Sciences. Stuttgart (Germany), - pp. 7173. (2014).

30. Lobachevskij Ja.P., Mamatov F., Jergashev I.T. Frontal'nyj plug dlja hlopkovodstva // - Hlopok, № 6.-pp 35-37. (1991).

31. Djuraev D., Khalilov M., Badalov S., Nurmonova M.Theoretical Determination Of The Power Consumption Of The Universal Mounted Sprayer Of PJG'-10// International Journal of Scientific \& Technology Research.- Vol. 9, Issue 2, - pp. 3797-3800. India, (2020).

32. Mamatov F., Djuraev D., Toirov I., Khalilov M., Rakhimov K. Parameters of a centrifugal sprayer fan for chemical processing of gardens //Journal of Critical Reviews.- China, (2020).-Vol.7, Issue 16, - Pp. 2966-2970. doi:10.31838/ jer.07.16.379.

33. Nevel'son M.I. Centrobezhnye ventiljatory. - Leningrad, p. 314. (1954).

34. Solomahova T.S., Chebysheva K.V. Centrobezhnye ventiljatory // Mashinostroenie. - S.26-28. Moskva, (1980).

35. Kalinushkin M.P. Ventiljatornye ustanovki. Vysshaja shkola.- pp.53-58. Moskva, (1962).

36. Ivanov O.P., Mamchenko V.O. Ajerodinamika i ventiljatory. Mashinostroenie. -p 280. Leningrad, (1986).

37. Turbin B.G. Ventiljatory sel'skohozjajstvennyh mashin. Mashinostroenie. p. 159. Leningrad, (1968).

38. Cherkasskij V.M i dr. Nasosy, kompressory, ventiljatory. Jenergija..- pp.80-115. Moskva, (1968).

39. I.N. Beleckij, A.K. Lysov, N. S Lepehin i dr. Mehanizacija zashhity rastenij, Spravochnik. - M.: Agropromizdat, - p. 14. (1992).

40. Solomahova T.S., Chebysheva K.V. Centrobezhnye ventiljatory, Mashinostroenie.p.26-28. -Moskva, (1980).

41. Irisov Kh.D., Ashirbekov I.A., Sherqobilov S.M., Begimkulov F.E. Optimization of turbulizator sprayer parameters by mathematical planning method of experiments, International Journal of Psychosocial Rehabilitation, Engineering Sciences, Great Britain, Vol. 24, Issue 06, pp. 9183-919, (2020) 